\title{
Purification and Functionalization of Single-Walled Carbon Nanotubes through Different Treatment Procedures
}

\author{
Peir-An Tsai, ${ }^{1}$ Hsuan-Yuan Kuo, ${ }^{2}$ Wei-Ming Chiu, ${ }^{2}$ and Jyh-Horng Wu ${ }^{3}$ \\ ${ }^{1}$ General Education Center, Jen-Teh Junior College of Medicine, Nursing and Management, Houlong, Miaoli County 35664, Taiwan \\ ${ }^{2}$ Department of Chemical and Materials Engineering, National Chin-Yi University of Technology, Taiping, Taichung 41111, Taiwan \\ ${ }^{3}$ Material Application Center, Industrial Technology Research Institute, Tainan 70955, Taiwan
}

Correspondence should be addressed to Wei-Ming Chiu; cwm@ncut.edu.tw and Jyh-Horng Wu; george6916@yahoo.com.tw

Received 29 November 2012; Accepted 28 January 2013

Academic Editor: Anukorn Phuruangrat

Copyright (C) 2013 Peir-An Tsai et al. This is an open access article distributed under the Creative Commons Attribution License, which permits unrestricted use, distribution, and reproduction in any medium, provided the original work is properly cited.

\begin{abstract}
Single-walled carbon nanotubes (SWCNTs) were purified by the combined use of ultrasonic- and microwave-assisted acid digestion. The results show that the method efficiently eliminates impurities, reduces solvent consumption, and prevents damage to the structure of the SWCNTs. The purified SWCNTs were given functionalization treatments with a nitric acid/sulfuric acid mixture. These acid-treated SWCNTs (A-SWCNTs) were then grafted with 3-isocyanatopropyl triethoxysilane (A-SWCNTs-Si). The A-SWCNTs and A-SWCNTs-Si were used to improve interfacial interactions with polymers and to produce a well-dispersed SWCNT composite.
\end{abstract}

\section{Introduction}

Carbon nanotubes (CNTs) are the focus of continued study, because of their structural, mechanical, and electronic properties $[1,2]$. Common methods of manufacturing CNTs include chemical vapor deposition [3, 4], arc-discharge [5$7]$, pyrolysis $[8,9]$, combustion $[10,11]$, glow discharge [12], and laser ablation [13]. However, the use of these methods to prepare CNTs always produces impurities, such as disordered carbon, graphite, fullerenes, and catalysts. The CNTs must be thoroughly purified, if they are to be used in a variety of projected applications and basic studies.

Many purification methods for the removal of impurities in CNTs have been investigated, such as physical separation [14], chemical oxidation [15, 16], and combinations of chemical and physical techniques [17, 18]. However, almost all of these methods are time consuming and require high temperature and large amounts of chemical reagents. They also damage the structure of the CNTs. Moreover, CNTs have inert surfaces and tend to agglomerate in organic solvents, making further processing difficult, or even impossible [19]. Therefore, CNTs are often functionalized using physical or chemical reactions.

This study proposes an efficient procedure for the purification of SWCNTs using a combination of ultrasonic-c and microwave-assisted acid digestion. After purification, thermo-gravimetric analysis (TGA), Raman spectroscopy, scanning electron microscopy (SEM) and transmission electron microscopy (TEM) were used to evaluate the efficiency of the purification, bonding structure, and morphology of SWCNTs. The purified SWCNTs were further functionalized using chemical reactions and examined by Fourier transform infrared (FTIR).

\section{Experimental}

2.1. Material. SWCNTs (diameter $<2 \mathrm{~nm}$, length: 5 to $15 \mu \mathrm{m}$, purity 95\%) were supplied by Scientech Co. Ltd, Taiwan. 3-isocyanatopropyltriethoxysilane (IPTES, purity > 95\%) was produced by TCI, Japan. Tetrahydrofuran (THF), acetone $\left(\mathrm{CH}_{3} \mathrm{COCH}_{3}\right)$, and potassium bromide $(\mathrm{KBr})$ were purchased from ECHO chemical Co. Ltd, Taiwan. Nitric acid $\left(\mathrm{HNO}_{3}\right.$, purity $\left.>98 \%\right)$ and sulfuric acid $\left(\mathrm{H}_{2} \mathrm{SO}_{4}\right.$, purity > 98\%) were purchased from Rich biotech Co. Ltd, Taiwan.

2.2. The Purification of SWCNTs Using Ultrasonic-Assisted Acid Digestion. $0.5 \mathrm{~g}$ SWCNTs was bath sonicated in $100 \mathrm{~mL}$ of $0.5 \mathrm{M} \mathrm{HNO}_{3}$, for $0.5 \mathrm{hr}$, and subsequently refluxed at $120^{\circ} \mathrm{C}$, for $24 \mathrm{hr}$. The solution was then filtered and rinsed with distilled water, until the $\mathrm{pH}$ of the filtrate was neutral. The 
TABLE 1: The TGA analysis of SWCNTs using a combination of ultrasonic and microwave for various treatment times ( $5,10,20$, and 30 min) with various $\mathrm{HNO}_{3}$ concentrations $(0.5,1$, and $3 \mathrm{M})$.

\begin{tabular}{|c|c|c|c|c|c|c|}
\hline \multirow{3}{*}{ Microwave treatment time (min) } & \multicolumn{6}{|c|}{$\mathrm{HNO}_{3}$ concentration $(\mathrm{M})$} \\
\hline & \multicolumn{2}{|c|}{$3 \mathrm{M}$} & \multicolumn{2}{|c|}{$1 \mathrm{M}$} & \multicolumn{2}{|c|}{$0.5 \mathrm{M}$} \\
\hline & $T_{\mathrm{d} 5}{ }^{\mathrm{a}}\left({ }^{\circ} \mathrm{C}\right)$ & Char yield (\%) & $T_{\mathrm{d} 5}\left({ }^{\circ} \mathrm{C}\right)$ & Char yield (\%) & $T_{\mathrm{d} 5}\left({ }^{\circ} \mathrm{C}\right)$ & Char yield (\%) \\
\hline 0 & 678.7 & 90.2 & 678.7 & 90.2 & 678.7 & 90.2 \\
\hline 5 & 619.6 & 86.6 & 655.9 & 89.0 & 692.2 & 91.1 \\
\hline 10 & 553.7 & 82.5 & 571.2 & 86.4 & 717.7 & 92.9 \\
\hline 20 & 522.8 & 81.3 & 534.8 & 84.2 & 815.9 & 95.7 \\
\hline 30 & 490.5 & 80.4 & 522.8 & 80.7 & 752.7 & 93.8 \\
\hline
\end{tabular}

${ }^{\mathrm{a}}$ Decomposition temperature at $5 \%$ weight loss.

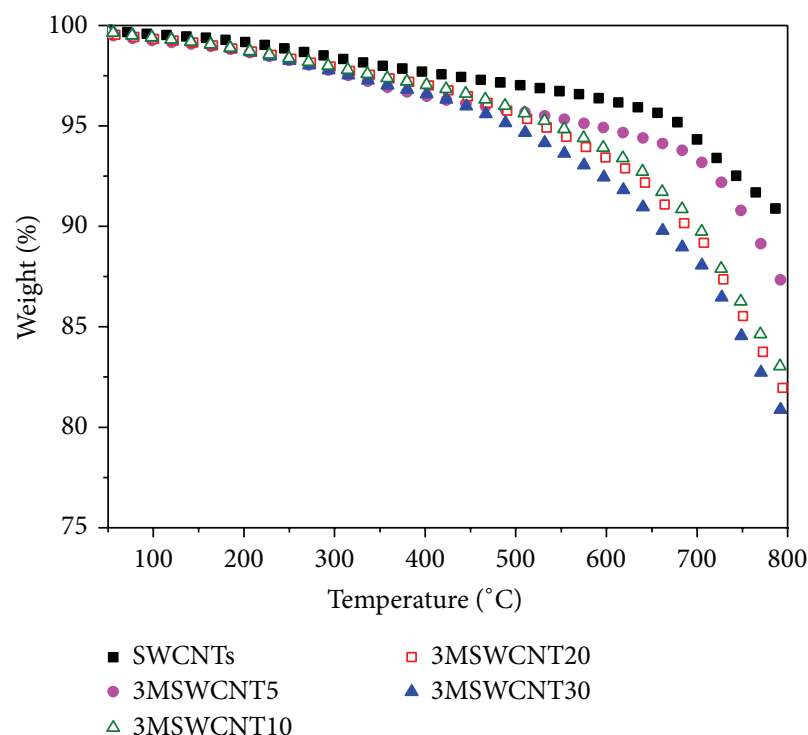

(a)

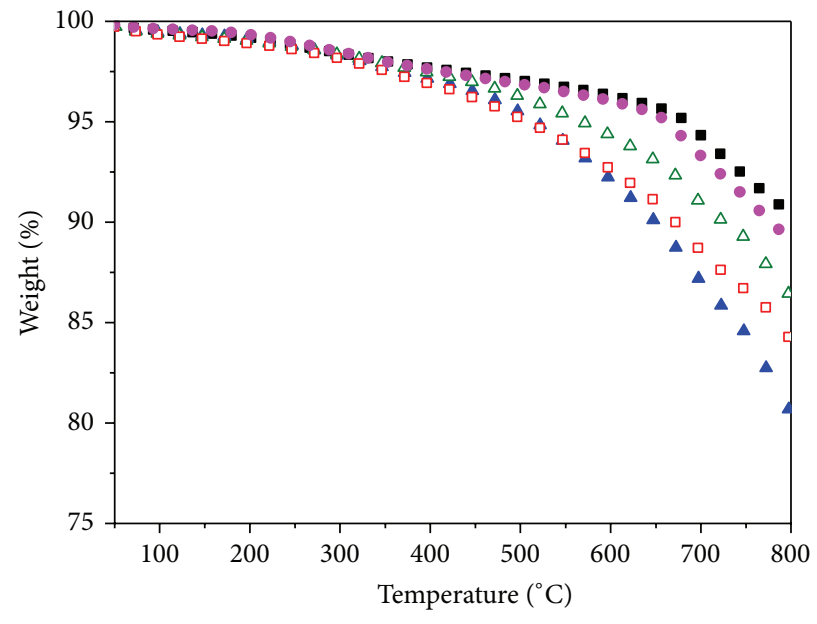

- SWCNTs

- 1MSWCNT5

$\square$ 1MSWCNT20

$\triangle$ 1MSWCNT10

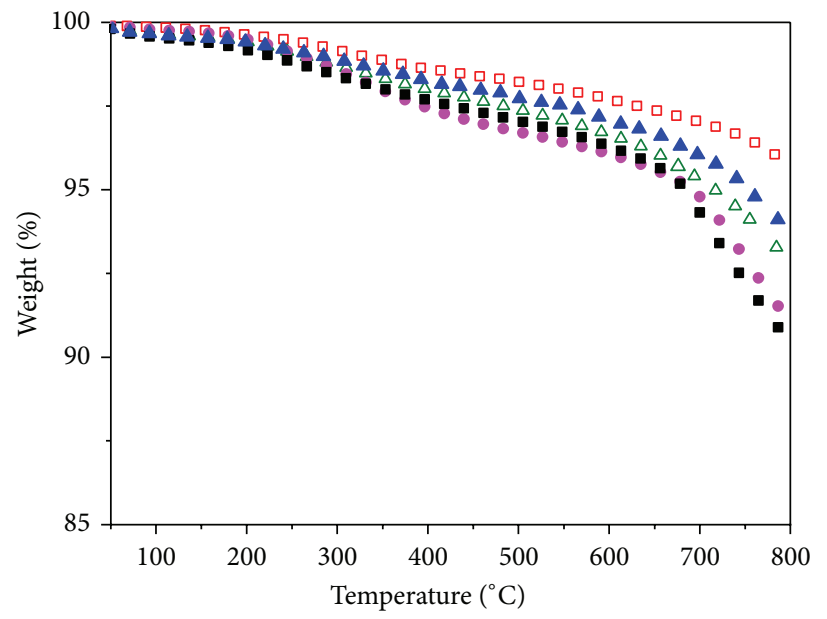

$\begin{array}{ll}\text { - SWCNTs } & \square 0.5 \text { MSWCNT20 } \\ \text { - } 0.5 \text { MSWCNT5 } & \triangle 0.5 \text { MSWCNT30 } \\ \triangle 0.5 \text { MSWCNT10 } & \end{array}$

(c)

FIGURE 1: The TGA traces of SWCNTs using a combination of ultrasonic and microwave for various treatment times (5, 10, 20 and 30 min) with various $\mathrm{HNO}_{3}$ concentrations: (a) 3, (b) 1 , and (c) $0.5 \mathrm{M}$. 
sample was bath sonicated in water, for $0.5 \mathrm{hr}$, and finally dried at $100^{\circ} \mathrm{C}$, for $12 \mathrm{hr}$. After drying, a thin, black mat comprised of cleaned SWCMTs (CSWCNTs) was obtained.

2.3. The Purification of SWCNTs by a Combination of Ultrasonic- and Microwave-Assisted Acid Digestion. $0.5 \mathrm{~g}$ of SWCNTs was bath sonicated in $100 \mathrm{~mL} \mathrm{HNO}_{3}(0.5,1$, and $3 \mathrm{M}$ ) for $0.5 \mathrm{hr}$. After sonication, the solution was purified by microwave-assisted purification, for 5, 10, 20, and $30 \mathrm{~min}$ at $120^{\circ} \mathrm{C}$, with the microwave power set to $300 \mathrm{~W}$. Then, the solution was filtered and rinsed with distilled water, until the $\mathrm{pH}$ of the filtrate was neutral. The sample was bath sonicated in water for $0.5 \mathrm{hr}$ and finally dried at $100^{\circ} \mathrm{C}$ for $12 \mathrm{hr}$. The resulting material was designated MSWCNTs and was used as the initial material for the following functionalization procedures.

2.4. Functionalization Treatment. The MSWCNTs were placed in an ultrasonic bath at $50^{\circ} \mathrm{C}$, for 2,5 , and $8 \mathrm{hr}$, with a $3: 1(\mathrm{v} / \mathrm{v})$ mixture of $\mathrm{H}_{2} \mathrm{SO}_{4}$ and $\mathrm{HNO}_{3}$. It was then filtered and rinsed with distilled water, until the $\mathrm{pH}$ of the filtrate was neutral. Finally, the sample was dried at $120^{\circ} \mathrm{C}$ in a vacuum, overnight. After drying, a thin, black mat designated for A-SWCNTs was obtained.

The A-SWCNT was subjected to an ultrasonic bath environment for $2 \mathrm{hr}$ with THF. It was then mixed with IPTES (A-SWCNTs/IPTES $=1: 2 ; \mathrm{v} / \mathrm{v}$ ), and the solution was subsequently refluxed at $65^{\circ} \mathrm{C}$, for $24 \mathrm{hr}$. This solution was then filtered, using a $200 \mathrm{~nm}$ pore size hydrolyzed polytetrafluoroethene (PTFE) membrane, and rinsed with THF. The functionalized A-SWCNTs (A-SWCNTs-Si) were then placed in an oven to remove the solvent and finally dried at $120^{\circ} \mathrm{C}$, for $12 \mathrm{hr}$.

2.5. Characterization. TGA was performed on a TA instrument (model number Q500), and the samples were heated from 50 to $800^{\circ} \mathrm{C}$ at a heating rate of $30^{\circ} \mathrm{C} \mathrm{min}{ }^{-1}$. Raman spectra were obtained using a Renishaw 1000 Raman spectrophotometer. The wavelength region of 1000 to $2000 \mathrm{~cm}^{-1}$ was investigated using a laser with a power of $0.3 \mathrm{Mw}$ and a wavelength of $633 \mathrm{~nm}$. Morphology was evaluated using a SEM (TOPCON ABT-150S) and TEM (JEOL JEM2010). FTIR spectra were recorded on a Nicolet320 FTIR spectrometer, using the $\mathrm{KBr}$ pellet technique.

\section{Results and Discussion}

3.1. TGA Analysis. Figures 1(a)-1(c) plot the TGA traces of SWCNTs using a combination of ultrasonic and microwave for various treatment times $(5,10,20$, and $30 \mathrm{~min})$ with various $\mathrm{HNO}_{3}$ concentrations $(0.5,1$, and $3 \mathrm{M})$. The variations in degradation temperature at $5 \%$ weight loss $\left(T_{\mathrm{d} 5}\right)$ and char yield are summarized in Table 1. Figure 1(a) shows that the $T_{\mathrm{d} 5}$ of SWCNTs at $678.7^{\circ} \mathrm{C}$ was due to the burning of amorphous carbon. An increase in temperature causes a sharp decrease in the weight of the SWCNTs during the oxidation of the SWCNTs. The $T_{\mathrm{d} 5}$ of SWCNTs decreases as
TABLE 2: Comparative TGA analysis of SWCNTs, 0.5MSWCNT20, and CSWCNTs.

\begin{tabular}{lccc}
\hline Item & SWCNTs & 0.5 MSWCNT20 & CSWCNTs \\
\hline$T_{\mathrm{d} 5}\left({ }^{\circ} \mathrm{C}\right)$ & 678.7 & 815.9 & 686.6 \\
Char yield (\%) & 90.2 & 95.7 & 88.0 \\
\hline
\end{tabular}

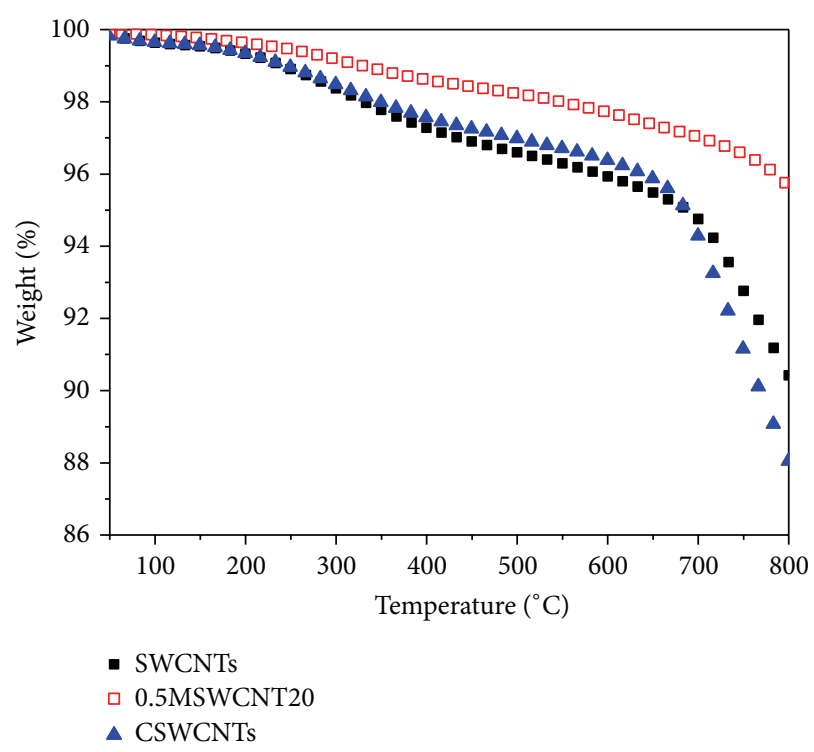

FIGURE 2: TGA traces of SWCNTs, 0.5MSWCNT20, and CSWCNTs.

the purification time is increased. This result clearly shows that excessive concentrations of $\mathrm{HNO}_{3}$ solution $(3 \mathrm{M})$ cause the surface structure of the SWCNTs to be destroyed and lead to functionalization at around $300^{\circ} \mathrm{C}$. After further dilution in $\mathrm{HNO}_{3}$ solution, Figure 1(b) shows that the purification of the SWCNTs by $1 \mathrm{M} \mathrm{HNO}_{3}$ solution has a less destructive effect than the $3 \mathrm{M} \mathrm{HNO}_{3}$ solution. Figure $1(\mathrm{c})$ shows the obvious increase in $T_{\mathrm{d} 5}$ for the SWCNTs purified by ultrasound and microwaves in $0.5 \mathrm{M} \mathrm{HNO}_{3}$ solution, which indicates that the MSWCNTs effectively remove amorphous carbon. Also, the increase was most pronounced when the purification treatment time was $20 \mathrm{~min}$ (0.5MSWCNT20), because the $0.5 \mathrm{MSWCNT} 20$ surface is composed of a stable carboncarbon structure, in which the $\mathrm{sp}^{2}$ bond forms a perfect hexagonal crystal structure.

Figure 2 plots the TGA traces of SWCNTs, 0.5MSWCNT20, and CSWCNTs. The variations in degradation temperature in 5\% and char yield are summarized in Table 2. The curve shows that a combination of ultrasound and microwave purification of SWCNTs is much more effective than ultrasonic purification alone. Therefore, this study takes no further interest in ultrasound purification.

3.2. Raman Analysis. Figures 3(a)-3(c) plot the Raman analysis of SWCNTs using a combination of ultrasonic and microwave treatment for various treatment times $(5,10$, 20, and $30 \mathrm{~min})$ with various $\mathrm{HNO}_{3}$ concentrations $(0.5$, 1 , and $3 \mathrm{M})$. In Figure $3(\mathrm{a})$, the graphitic band $(\mathrm{G})$ peak decreases proportionally and the disorder band (D) increases 


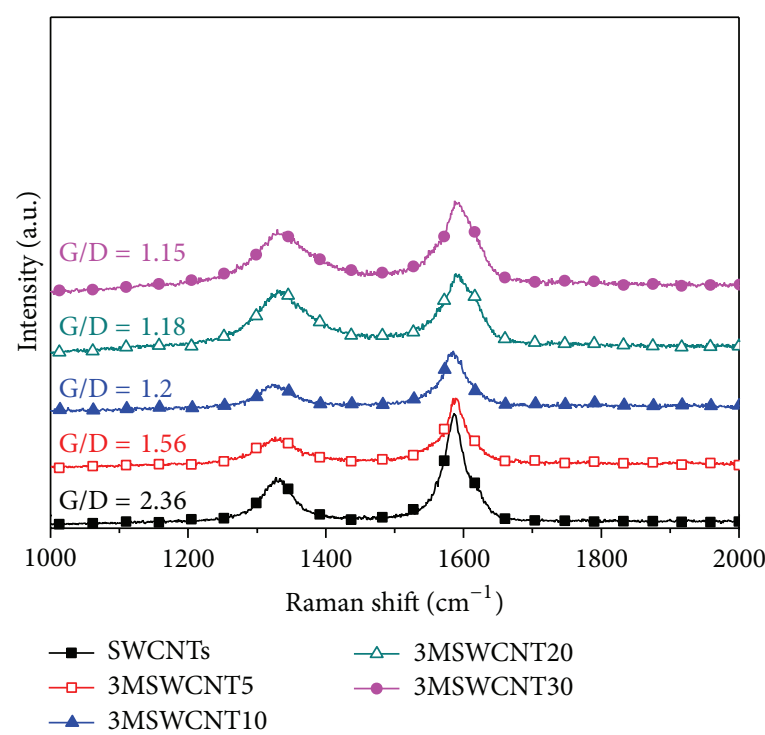

(a)

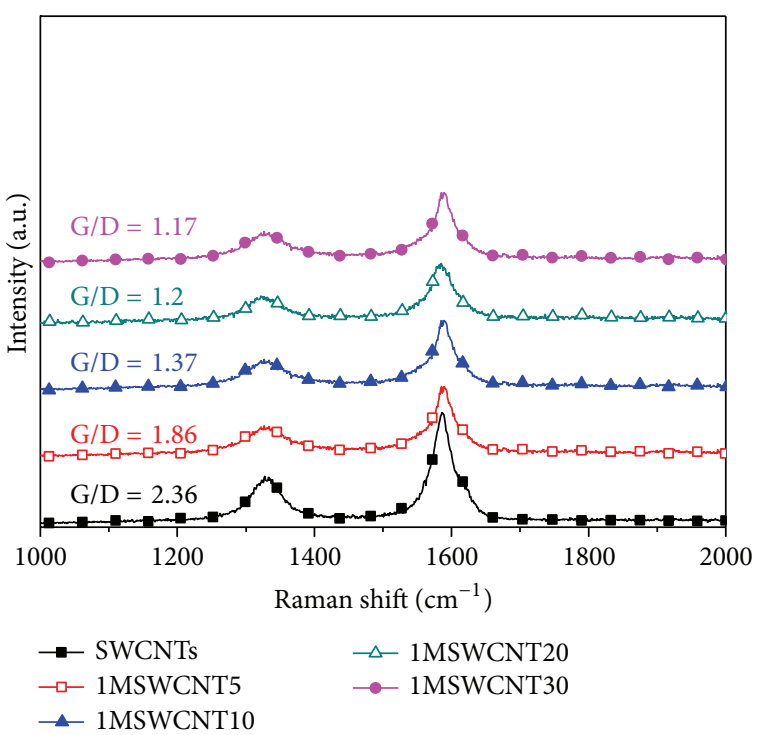

(b)

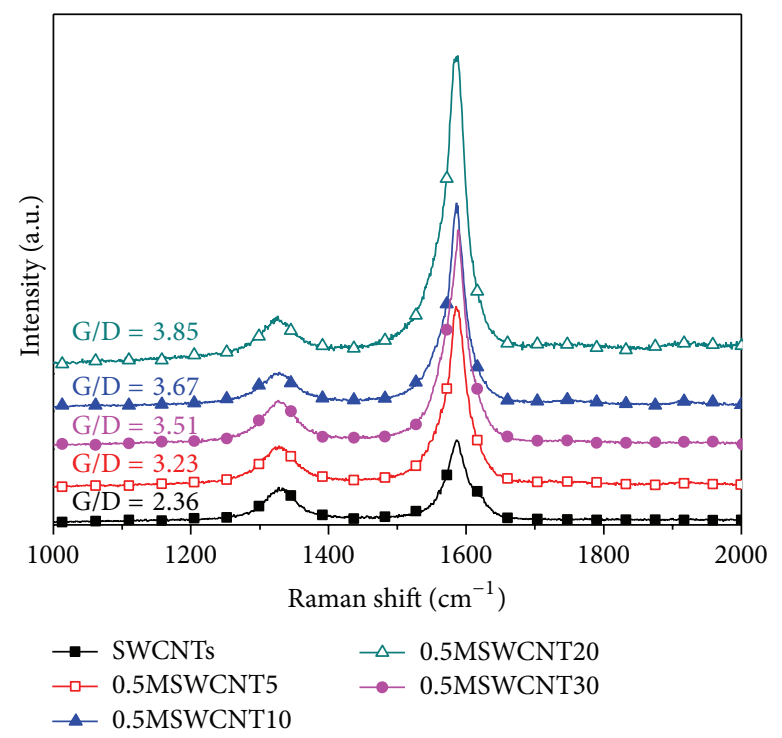

(c)

FIGURE 3: The Raman analysis of SWCNTs using a combination of ultrasonic and microwave treatment for various treatment times $(5,10,20$, and 30 min) with various $\mathrm{HNO}_{3}$ concentrations: (a) 3, (b) 1, and (c) $0.5 \mathrm{M}$.

proportionally as the purification treatment time is increased. The G/D ratio decreases from 2.36 to 1.15 . Figure $3(\mathrm{~b})$ shows that the G/D ratio of SWCNTs is a little higher than that for a $3 \mathrm{MHNO}_{3}$ concentration, which indicates that purification has not yet been achieved. In addition, the G/D ratio from $3 \mathrm{M}$ and $1 \mathrm{MHNO}_{3}$ was lower than SWCNTs, which indicates that high acid treatment concentration and long acid treatment time would result in the break of tubes. Figure 3(c) shows an obvious increase in the G/D ratio from 2.36 to 3.85 , when the SWCNTs are purified by ultrasound and microwave treatment with a $0.5 \mathrm{M} \mathrm{HNO}_{3}$ concentration. The G/D ratio from $0.5 \mathrm{M} \mathrm{HNO}_{3}$ was higher than SWCNTs, which indicates efficient elimination of amorphous carbon without damage to the structure of the tubes and strengthens the three-dimensional structure of SWCNTs. These results are consistent with those of the TGA analysis.

In order to enhance the MSWCNTs dispersion in solution and to improve their interfacial interactions with polymers, the MSWCNTs were functionalized using an oxidative process with a mixture of $\mathrm{H}_{2} \mathrm{SO}_{4}$ and $\mathrm{HNO}_{3}$ (A-SWCNTs). Figure 4 shows the Raman analysis results, which show a higher D peak for the SWCNTs than the A-SWCNTs at $1582 \mathrm{~cm}^{-1}$. This is due to the mixture of $\mathrm{H}_{2} \mathrm{SO}_{4}$ and $\mathrm{HNO}_{3}$, which breaks the carbon-carbon double bonds and causes the $\mathrm{G} / \mathrm{D}$ ratio to be decreased from 2.36 to 1.09 .

3.3. FTIR Spectral Analysis. The functionalization of the SWCNTs' outer surface was examined by FTIR spectroscopy. 


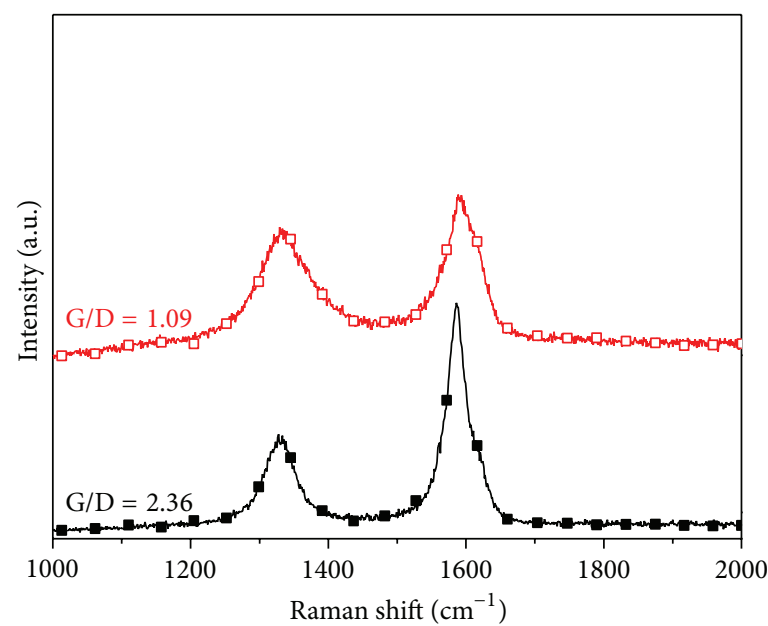

MSWCNTs

$\rightarrow-$ A-SWCNTs

FIgURE 4: The Raman curves of MSWCNTs and A-SWCNTs.

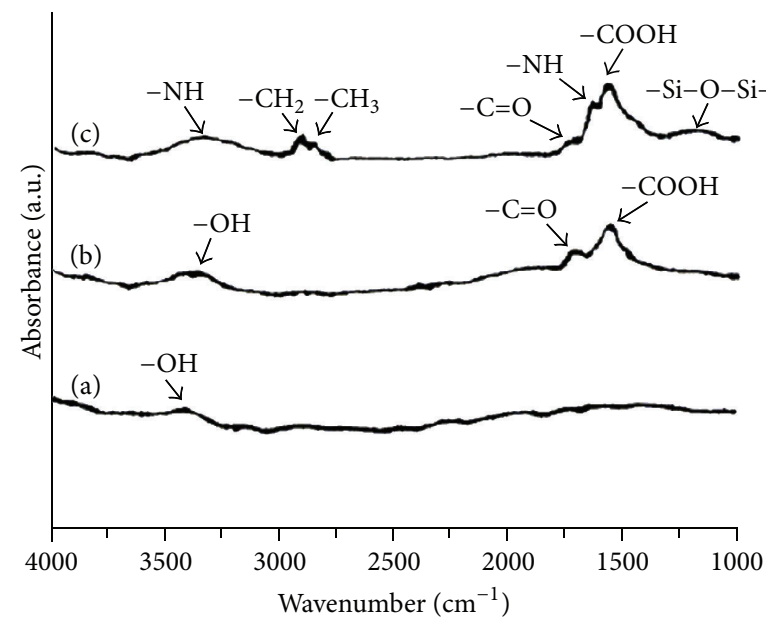

FIgURE 5: The FTIR curves of (a) MSWCNTs, (b) A-SWCNTs, and (c) A-SWCNTs-Si.

The FTIR spectra of (a) MSWCNTs, (b) A-SWCNTs, and (c) A-SWCNTs-Si are presented in Figure 5. Figure 5(a) shows the characteristic peaks of SWCNTs that appear at 3400 to $3500 \mathrm{~cm}^{-1}$, due to hydroxyl group stretching [20]. Figure 5(b) shows the main characteristic peaks of A-SWCNTs, which occur at 1550,1740, and $3400 \mathrm{~cm}^{-1}$, which can be assigned to carboxylic acid $(-\mathrm{COOH})$, carbonyl groups $(\mathrm{C}=\mathrm{O})$ and hydroxyl groups $(-\mathrm{OH})$, respectively. The $\mathrm{C}=\mathrm{O}$ and $-\mathrm{OH}$ on the A-SWCNTs' surface show enhanced dispersion in solution and increases in the intermolecular hydrogen bonds, when blended in polymers. This also helps the A-SWCNTs to graft to other functional groups.

Figure 5(c) shows that the main characteristic peaks of A-SWCNTs-Si, which occur at 2850 and $2930 \mathrm{~cm}^{-1}$, are methyl group $(-\mathrm{CH} 3)$ stretching. The characteristic peaks at 3350 and $1600 \mathrm{~cm}^{-1}$ are amino group $(-\mathrm{NH})$ stretching, which indicates that the $-\mathrm{COOH}$ groups of A-SWCNTs were efficient reacted with isocynate (-NCO) ends of IPTES.
The characteristic peak at $1550 \mathrm{~cm}^{-1}$ is $\mathrm{C}=\mathrm{O}$. This can be attributed to the residual-COOH groups on the A-SWCNTsSi surface that have not reacted completely with IPTES. The characteristic peak at $1180 \mathrm{~cm}^{-1}$ is $\mathrm{Si}-\mathrm{O}-\mathrm{Si}$ [21].

3.4. Morphology. Figure 6 shows the (a) SEM and (b) TEM images for SWCNTs. It is clearly seen that the SWCNTs are arranged in a disorderly manner (entanglement) and that impurities are present (amorphous carbon and metal particles). Figures 7-9 present the SEM images for SWCNTs using a combination of ultrasonic and microwave treatment for various treatment times: (a) 5, (b) 10, (c) 20, and (d) 30 min, with various $\mathrm{HNO}_{3}$ concentrations $(0.5,1$, and $3 \mathrm{M})$. In Figure 7, it is seen that the SWCNTs' surface structures are damaged by purification treatment. The damage is caused by excessive $\mathrm{HNO}_{3}$ concentrations. When there is dilution of the $\mathrm{HNO}_{3}$ solution, Figure 8 illustrates that the SWCNTs' surface structures exhibit less damage than with the 


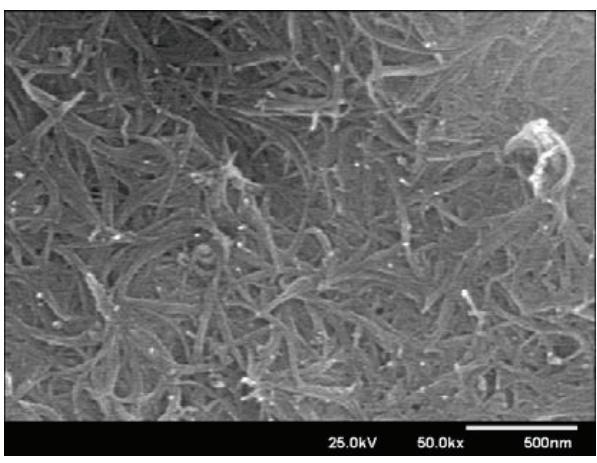

(a)

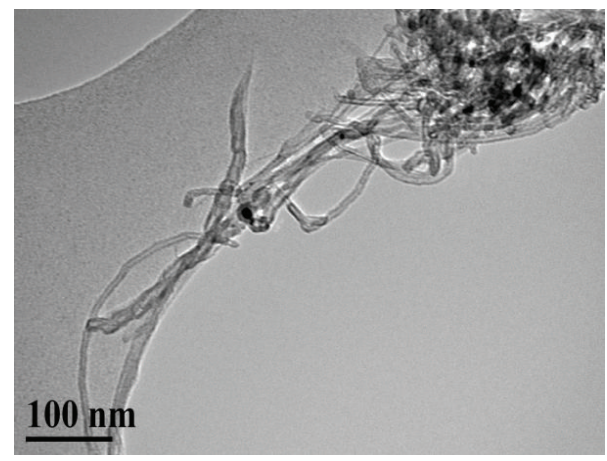

(b)

Figure 6: The (a) SEM and (b) TEM images for SWCNTs.

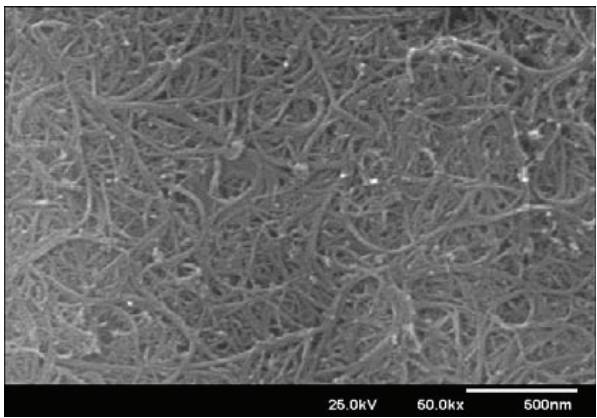

(a)

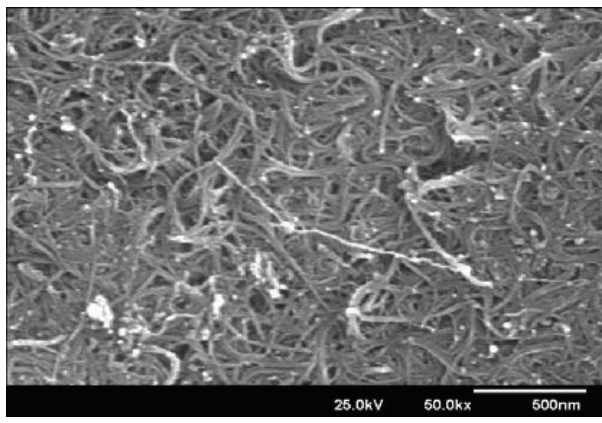

(c)

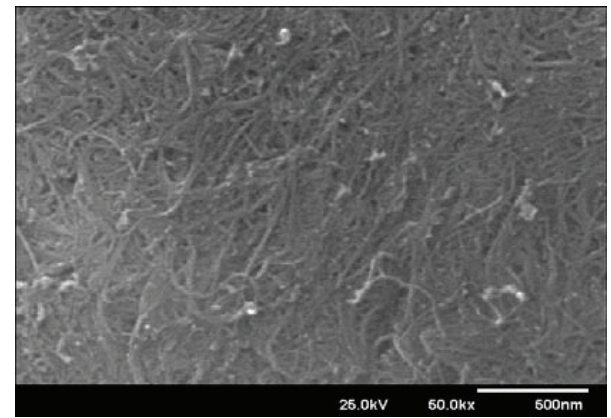

(b)

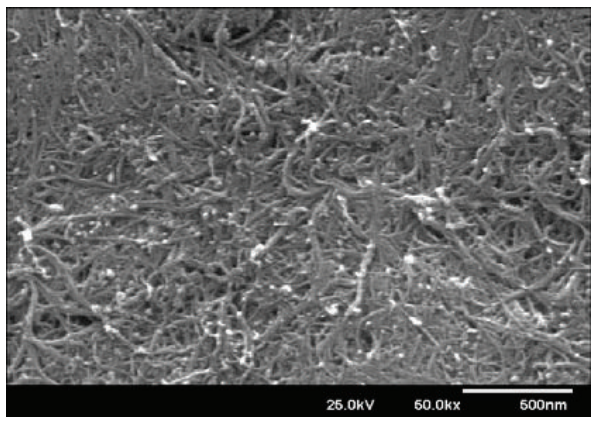

(d)

FIGURE 7: The SEM images of SWCNTs using a combination of ultrasonic and microwave for various treatment times: (a) 5 min, (b) 10 min, (c) $20 \mathrm{~min}$, and (d) $30 \mathrm{~min}$ with $3 \mathrm{M} \mathrm{HNO}_{3}$ concentration.

$3 \mathrm{M} \mathrm{HNO}_{3}$ purification solution. Figure 9 indicates obvious improvements in the entanglement and no damage to the SWCNTs purified by ultrasound and microwaves in $0.5 \mathrm{M}$ $\mathrm{HNO}_{3}$ solution for 20 min.

Figures 10(a)-10(d) show the SEM and TEM images of 0.5 MSWCNT2 0 for various treatment times with a $3: 1(\mathrm{v} / \mathrm{v})$ mixture of $\mathrm{H}_{2} \mathrm{SO}_{4}$ and $\mathrm{HNO}_{3}$ (A-SWCNTs). Figure 10(a) shows that the surface and length of the A-SWCNTs' are damaged and unevenly truncated, due to acid digestion for $2 \mathrm{hr}$. Figure 10(b) shows that the length of the tubes is more evenly truncated, but the original A-SWCNTs shapes are not lost by acid digestion for $5 \mathrm{hr}$. Figure 10(c) shows that the A-SWCNTs are destroyed by acid digestion for $8 \mathrm{hr}$. This indicates that the acid digestion time is too long and that the A-SWCNTs are too truncated. To determine, in more detail, the morphologies of the A-SWCNTs that are subject to acid digestion for $5 \mathrm{hr}$, the TEM image in Figure 10(d) shows that most of the impurities have been removed and that the clustering of A-SWCNTs is significantly improved, but that the surfaces of the A-SWCNTs are not smooth (laminated structures appear). These results are consistent with those for the Raman analysis.

Figure 11 presents the (a) SEM and (b) TEM images for A-SWCNTs-Si. It can be seen that A-SWCNTs-Si are entangled, compared to the A-SWCNTs (Figure 10(d)). The results indicate the attachment of silane molecules to the surface of the functionalized A-SWCNTs. These results are confirmed by FTIR analysis. 


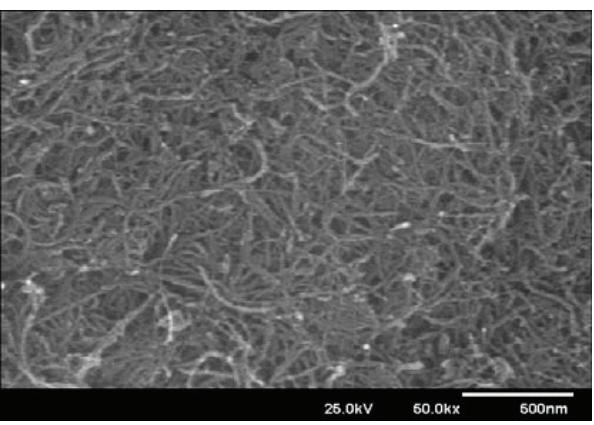

(a)

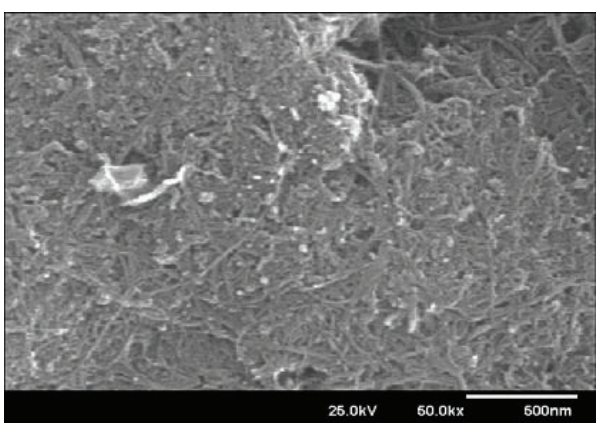

(c)

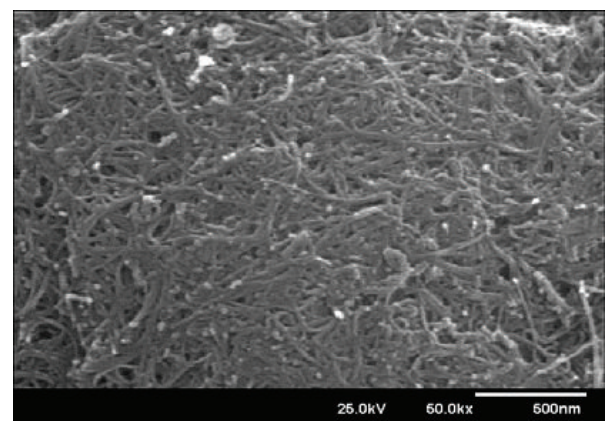

(b)

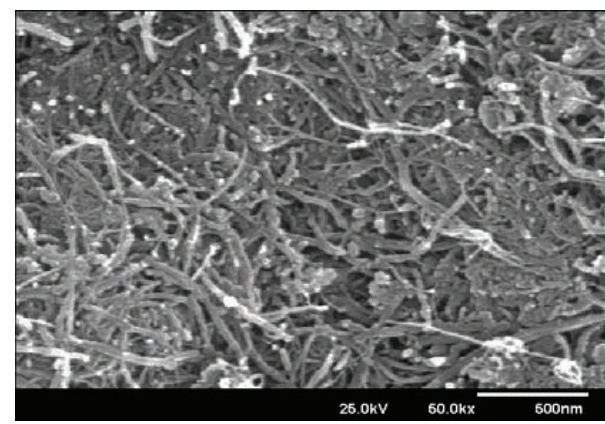

(d)

FIGURE 8: The SEM images of SWCNTs using a combination of ultrasonic and microwave for various treatment times: (a) 5 min, (b) 10 min, (c) $20 \mathrm{~min}$, and (d) $30 \mathrm{~min}$ with $1 \mathrm{M} \mathrm{HNO}_{3}$ concentration.

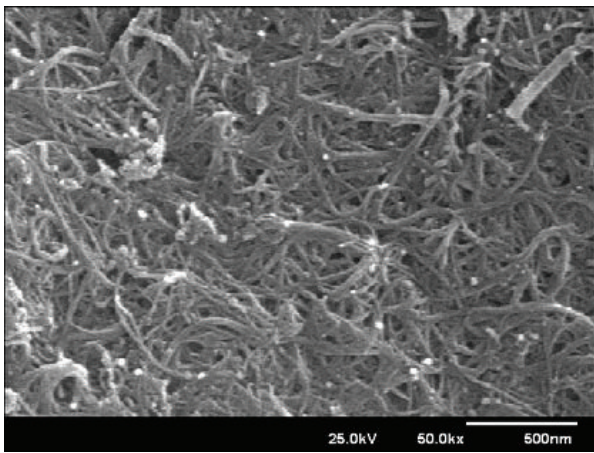

(a)

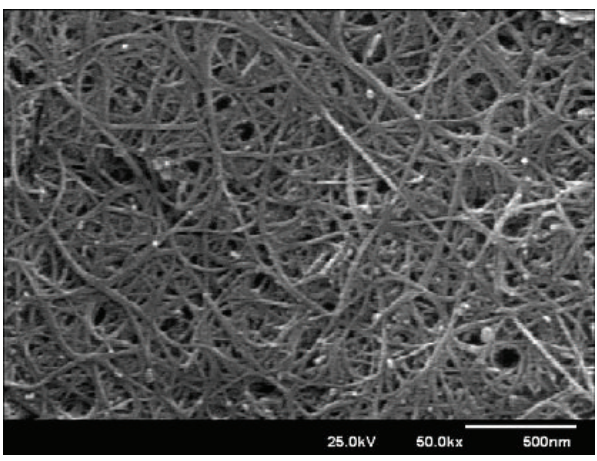

(c)



(b)

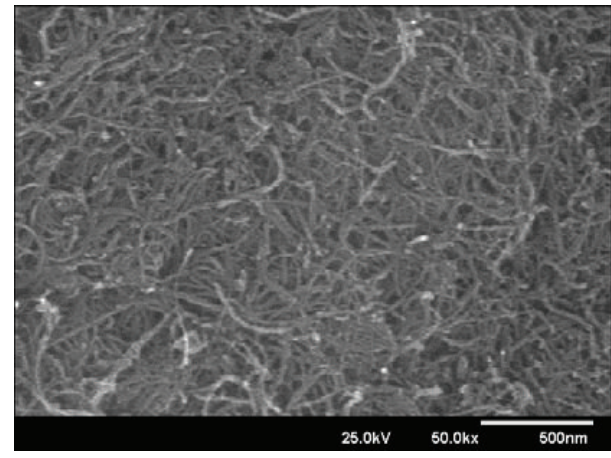

(d)

FIGURE 9: The SEM images of SWCNTs using a combination of ultrasonic and microwave for various treatment times: (a) 5 min, (b) 10 min, (c) $20 \mathrm{~min}$, and (d) 30 min with $0.5 \mathrm{M} \mathrm{HNO}_{3}$ concentration. 


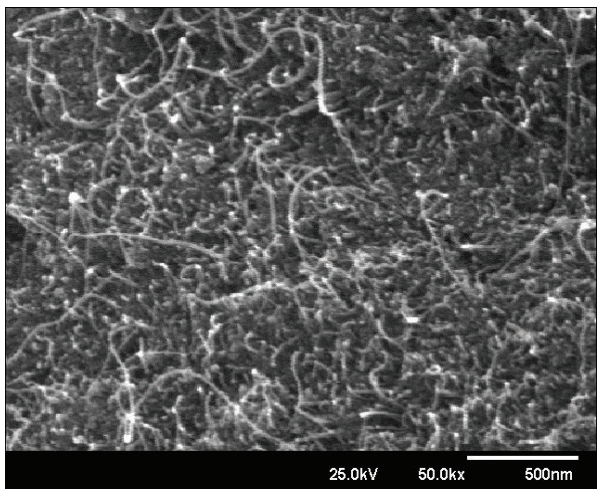

(a)

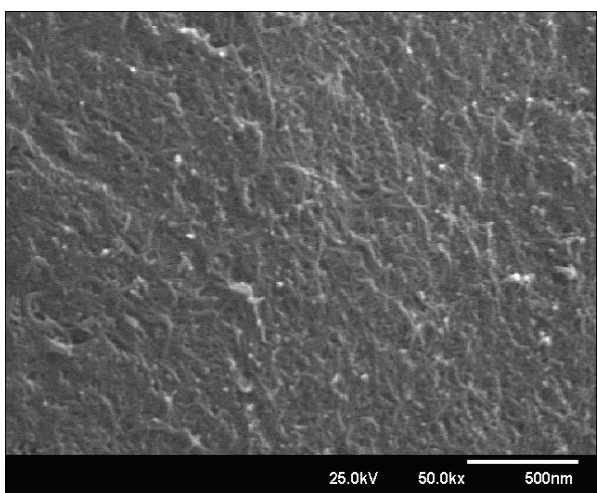

(c)

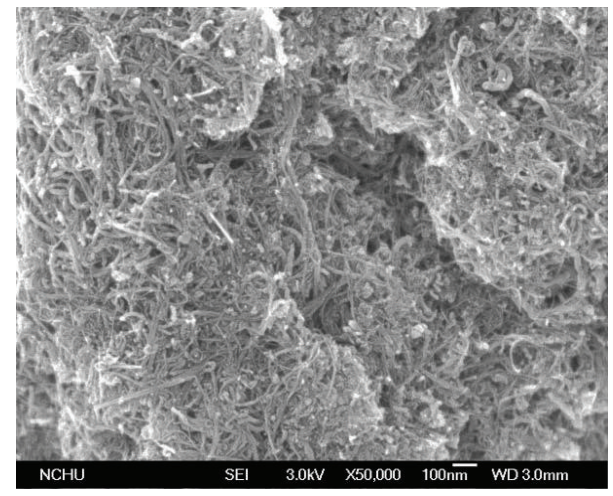

(b)

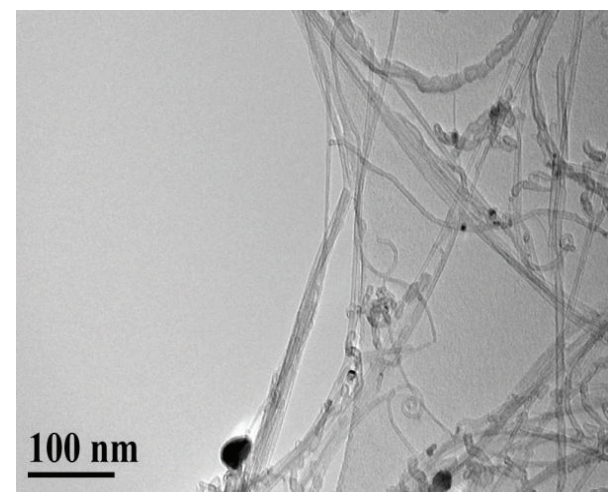

(d)

FIGURE 10: The SEM images of 0.5MSWCNT20 for various treatment times: (a) 2, (b) 5, and (c) 8 h and TEM image of 0.5 MSWCNT20 for (d) $5 \mathrm{~h}$ treatment times, with a $3: 1(\mathrm{v} / \mathrm{v})$ mixture of $\mathrm{H}_{2} \mathrm{SO}_{4}$ and $\mathrm{HNO}_{3}$.



(a)

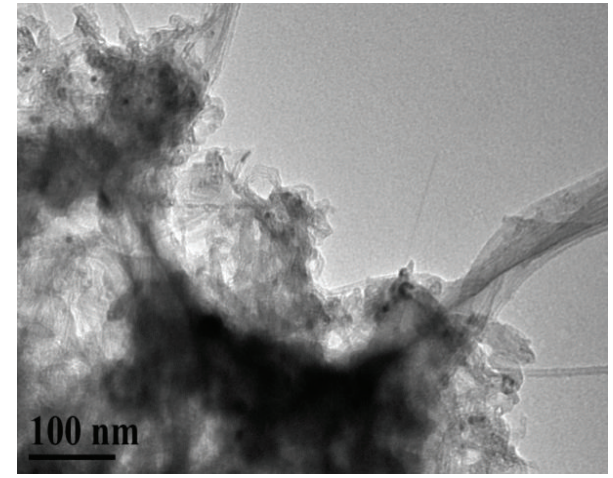

(b)

Figure 11: The (a) SEM and (b) TEM images for A-SWCNTs-Si. 


\section{Conclusion}

The purification and functionalization of SWCNTs using different treatment procedures were investigated. The optimization of the purified SWCNTs was combined using ultrasonic- and microwave-assisted acid digestion in $0.5 \mathrm{M}$ of $\mathrm{HNO}_{3}$ for $20 \mathrm{~min}$, which ensured the efficient elimination of impurities and prevention of damage to the structure of the SWCNTs. The purified SWCNTs were heated in an ultrasonic bath at $50^{\circ} \mathrm{C}$ for $5 \mathrm{hr}$ with a $3: 1(\mathrm{v} / \mathrm{v})$ mixture of $\mathrm{H}_{2} \mathrm{SO}_{4}$ and $\mathrm{HNO}_{3}$ to produce A-SWCNTs. Then, the A-SWCNTs were also grafted with IPTES to produce SWCNTs-Si. The ASWCNTs and A-SWCNTs-Si were used to improve interfacial interactions with polymers, and to produce a well-dispersed SWCNT composite, which will be the focus of future work.

\section{References}

[1] M. M. J. Treacy, T. W. Ebbesen, and J. M. Gibson, "Exceptionally high Young's modulus observed for individual carbon nanotubes," Nature, vol. 381, no. 6584, pp. 678-680, 1996.

[2] B. Liu, H. Jiang, H. T. Johnson, and Y. Huang, "The influence of mechanical deformation on the electrical properties of single wall carbon nanotubes," Journal of the Mechanics and Physics of Solids, vol. 52, no. 1, pp. 1-26, 2004.

[3] P. Ciambelli, D. Sannino, M. Sarno, C. Leone, and U. Lafont, "Effects of alumina phases and process parameters on the multiwalled carbon nanotubes growth," Diamond and Related Materials, vol. 16, no. 4-7, pp. 1144-1149, 2007.

[4] E. Flahaut, C. Laurent, and A. Peigney, "Catalytic CVD synthesis of double and triple-walled carbon nanotubes by the control of the catalyst preparation," Carbon, vol. 43, no. 2, pp. 375-383, 2005.

[5] T. Zhao and Y. Liu, "Large scale and high purity synthesis of single-walled carbon nanotubes by arc discharge at controlled temperatures," Carbon, vol. 42, no. 12-13, pp. 2765-2768, 2004.

[6] M. Yao, B. Liu, Y. Zou et al., "Synthesis of single-wall carbon nanotubes and long nanotube ribbons with $\mathrm{Ho} / \mathrm{Ni}$ as catalyst by arc discharge," Carbon, vol. 43, no. 14, pp. 2894-2901, 2005.

[7] L. Huang, B. Wu, J. Chen et al., "Synthesis of single-walled carbon nanotubes by an arc-discharge method using selenium as a promoter," Carbon, vol. 49, pp. 4792-4800, 2011.

[8] A. Aguilar-Elguézabal, W. Antúnez, G. Alonso, F. P. Delgado, F. Espinosa, and M. Miki-Yoshida, "Study of carbon nanotubes synthesis by spray pyrolysis and model of growth," Diamond and Related Materials, vol. 15, no. 9, pp. 1329-1335, 2006.

[9] I. Khatri, T. Soga, T. Jimbo, S. Adhikari, H. R. Aryal, and M. Umeno, "Synthesis of single walled carbon nanotubes by ultrasonic spray pyrolysis method," Diamond and Related Materials, vol. 18, no. 2-3, pp. 319-323, 2009.

[10] H. Okuno, J. P. Issi, and J. C. Charlier, "Catalyst assisted synthesis of carbon nanotubes using the oxy-acetylene combustion flame method," Carbon, vol. 43, no. 4, pp. 864-866, 2005.

[11] Z. Jiang, R. Song, W. Bi, J. Lu, and T. Tang, "Polypropylene as a carbon source for the synthesis of multi-walled carbon nanotubes via catalytic combustion," Carbon, vol. 45, no. 2, pp. 449-458, 2007.

[12] T. Nozaki and K. Okazaki, "Carbon nanotube synthesis in atmospheric pressure glow discharge: a review," Plasma Processes and Polymers, vol. 5, no. 4, pp. 300-321, 2008.
[13] T. F. Kuo, C. C. Chi, and I. N. Lin, "Synthesis of carbon nanotubes by laser ablation of graphites at room temperature," Japanese Journal of Applied Physics, vol. 40, no. 12, pp. 7147-7150, 2001.

[14] L. A. Montoro, C. A. Luengo, J. M. Rosolen, E. Cazzanelli, and G. Mariotto, "Study of oxygen influence in the production of single-wall carbon nanotubes obtained by arc method using $\mathrm{Ni}$ and Y catalyst," Diamond and Related Materials, vol. 12, no. 3-7, pp. 846-850, 2003.

[15] Y. Li, X. Zhang, J. Luo et al., "Purification of CVD synthesized single-wall carbon nanotubes by different acid oxidation treatments," Nanotechnology, vol. 15, no. 11, pp. 1645-1649, 2004.

[16] A. Suri and K. S. Coleman, "The superiority of air oxidation over liquid-phase oxidative treatment in the purification of carbon nanotubes," Carbon, vol. 49, no. 9, pp. 3031-3038, 2011.

[17] F. H. Ko, C. Y. Lee, C. J. Ko, and T. C. Chu, "Purification of multiwalled carbon nanotubes through microwave heating of nitric acid in a closed vessel," Carbon, vol. 43, no. 4, pp. 727-733, 2005.

[18] K. J. MacKenzie, O. M. Dunens, M. J. Hanus, and A. T. Harris, "Optimisation of microwave-assisted acid digestion for the purification of supported carbon nanotubes," Carbon, vol. 49, no. 13, pp. 4179-4190, 2011.

[19] J. L. Bahr, E. T. Mickelson, M. J. Bronikowski, R. E. Smalley, and J. M. Tour, "Dissolution of small diameter single-wall carbon nanotubes in organic solvents?" Chemical Communications, no. 2, pp. 193-194, 2001.

[20] C. A. Capozzi, R. A. Condrate, and L. D. Dye, "Hapannowicz, vibrational spectral/structural changes from the hydrolysis/polycondensation of methyl-modified silicates IV. IR spectral comparisons from the tetramethoxysilane/methyltrimethoxysilane/diethoxydimethylsilane system," Materials Letters, vol. 18, no. 5, pp. 349-352, 1994.

[21] S. Yan, W. Ling, and E. Zhou, "Rapid synthesis of $\mathrm{Mn}_{0.65} \mathrm{Zn}_{0.35} \mathrm{Fe}_{2} \mathrm{O}_{4} / \mathrm{SiO}_{2}$ homogeneous nanocomposites by modified sol-gel auto-combustion method," Journal of Crystal Growth, vol. 273, no. 1-2, pp. 226-233, 2004. 



Submit your manuscripts at http://www.hindawi.com


\section{The Scientific World Journal}
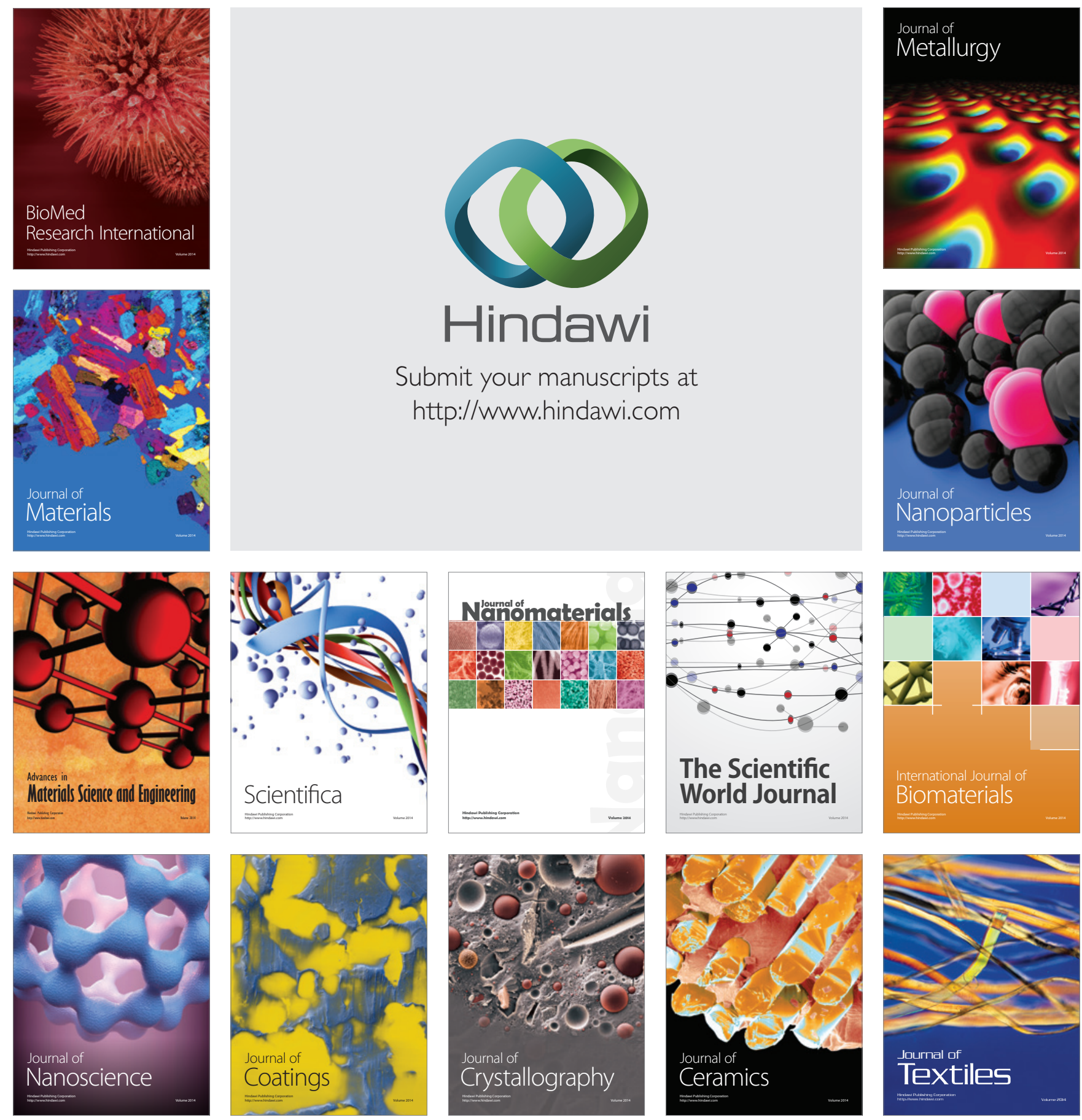